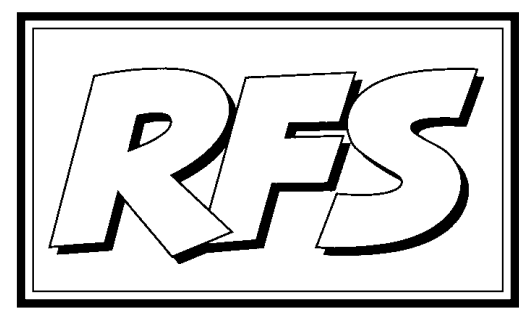

Revista de Fomento Social, 56 (2001), 555-589

\title{
Migraciones, multiculturalidad y políticas de identidad ${ }^{1}$
}

Stefano ZAMAGNI ${ }^{2}$

\section{Introducción y motivación}

Es un hecho, hoy por muchos reconocido, que en la época de la mundialización ${ }^{3}$ el fenómeno migratorio está destinado a adquirir una progresiva normalidad y a dejar de ser un acontecimiento excepcional o transitorio. Si en algunos segmentos de la población europea, e italiana en particular, está todavía extendido el convencimiento de que la cuestión de la inmigración será resuelta con simples políticas de acogida, esto se debe básicamente a

1 Catedrático de Ciencias Económicas de la Universidad de Bolonia y presidente, desde 1999, de la Commissione Cattolica Internazionale per le Migrazioni. En el origen del artículo está la conferencia pronunciada en la reunión del "Grupo de trabajo de Asuntos Sociales" de la COMECE en Rotterdam (noviembre de 2001).

2 Versión castellana del original italiano de José Ma Margenat SJ .

3 Globalizzazione en el original; si no se indica lo contrario traducimos siempre por mundialización. 
que, sólo en estos últimos años, el proceso de mundialización está empezando a ser considerado por la opinión pública popular. De ahí esa tardanza cultural quehace que muchos aún no puedan comprender plenamente cómo, en paralelo a un proceso emergente, económico, financiero e informativo, a escala planetaria, la mundialización pone en movimiento otro proceso, simétrico respecto al primero: la localización.

Dehecho, la estrecha interconexión e intersección de ambos procesos dan lugar a esa duplicidad de juicios sobre la mundialización, que acabamos de señalar: para unos setrata de una nueva conquista, para otros representa una nueva vinculación a la dimensión local; si la mundialización señala nuevos espacios de libertad para algunos, para otros significa sumisión a un destino no buscado; ocurre lo mismo en otros aspectos. Como bien aclara Bauman, en un ensayo $0^{4}$ específicamente dedicado al estudio de las consecuencias de la mundialización sobre las personas, la movilidad es el nuevo y principal factor de estratificación social en la era de la mundialización: algunos grupos sociales llegan a ser "globales", otros están ligados a la propia localidad, pero son los "globales" los que fijan las reglas del juego de la vida, casi siempre no escritas, que los "locales" están obligados a sufrir. Seguir siendo "locales" en un mundo "global" es signo de inferioridad y, al tiempo, causa de un nuevo sufrimiento; el que está constreñido a vivir en un lugar, hoy se da cuenta de que los lugares locales están perdiendo la capacidad de generar sentido y de atribuir significados a la existencia. De ahí surgen, según el sociólogo polaco, las tendencias al neotribalismo y al fundamentalismo de los que recibimos en los medios triste confirmación diaria.

Es un hecho que la mundialización va creando una nueva causa de segregación y de exclusión y, por eso, nuevas formas de pobreza, una causa que se manifiesta en la libertad de movimiento, que resulta posible para algunos y negada a otros. El poderoso del pasado era quien podía construirse el castillo para defender su territorio; el rico de hoy es quien vive sin límites; quien no tiene ya un territorio que defender. No sólo, pero lo que esta situación más revela es que los centros donde son "producidas" las normas sociales del comportamiento, los valores, los estilos de vida, son actualmente extraterritoriales y están separados de los vínculos locales, mientras, ciertamente, no es extraterritorial la condición de vida de aquellos que están ligados a un lugar específico. Estos se ven obligados entonces a atribuir un sentido a modos de vida que no les son propios, sino importados de otros

4 Z. Bauman (2000), Dentro la globalizzazione: le conseguenze sulle persone, Roma, Laterza. 
lugares. En esto reside el origen del desarraigo, de la pérdida de raíces de grupos sociales cada vez más numerosos. Para decirlo de otro modo, la mundialización va creando una creciente separación entre los lugares de producción de la cultura y los lugares de disfrute de la misma; el conocido fenómeno de la desterritorialización no se refiere sólo a las empresas que pueden decidir con relativa desenvoltura dónde localizar las propias actividades productivas, sino también a la cultura. Como ejemplifica con eficacia el antropólogo Appadurai, el emigrante turco puede hoy ver en su casa de Alemania películas turcas en lengua original ${ }^{5}$.

A la luz de esto, es fácil comprender que la tesis de la continuidad entre las migraciones de hoy y las primeras migraciones masivas del siglo XIX y primer tercio del siglo XX Ileva a la confusión. Cuando se dice que el emigrante de hoy casi nunca es el más pobre o el menos integrado culturalmente en su propia comunidad de origen, o cuando se dicequesería pura ilusión pensar en alentar la presión migratoria acelerando el proceso de desarrollo en los países generadores de flujos migratorios, se sostienen posiciones correctas y relevantes. Más allá de esto, sin embargo, lo más claro es que en el curso de más de un siglo ha cambiado radicalmente el modelo de comportamiento del inmigrado. Como recuerda Lepenis ${ }^{6}$, el inmigrante de hace un tiempo intentaba asimilarse lo más rápidamente posibley lograr una nueva aculturación: tras el corte limpio (clean break) con el país de origen, la apertura a los usos y costumbres de la nueva patria constituía el presupuesto para el éxito económico y para el reconocimiento social. Hoy, la inmigración no representa de ninguna manera, o por lo menos no necesariamente, la aspiración a un punto de no retorno (point of no return). Las posibilidades de los desplazamientos de masas y las nuevas tecnologías infotelemáticas han creado una sociedad delas migraciones en que los habitantes siguen siendo, con notable flexibilidad, ciudadanos de dos mundos, por hablar de alguna forma. En el plano de la actuación política los inmigrantes adquieren los modos del país de acogida, pero en el plano de los valores y de los sentimientos morales pretenden permanecer fieles a su cultura de origen. Antes bien, estamos orgullosos de exhibir, en la esfera pública, las propias diversidades culturales. Tanto en los EE.UU de Norteamérica como en Europa, se nota en nuestro tiempo que muchos inmigrados hacen ostentación de una etnicidad expresiva ${ }^{7}$, que toma

\footnotetext{
5 A. Appadural (2000), Modernità in polvere, Milán, Meltemi.

6 W. LePENIS, “Multiculturalità e globalizzazione”, en II Sole 24 Ore, 31-XII-2000.

7 "Expressive ethnicity" en el original.
} 
el relevo al deseo de una adaptación perfecta.

¿Qué es un país si no es una nación y qué es una cultura si no es un consenso?, se pregunta el conocido antropólogo Geertz en un reciente ensay $0^{8}$. Todavía en un pasado cercano preguntas de este tipo hubiesen carecido de sentido: los países eran naciones, las culturas eran estilos devida compartidos. La novedad profunda de la economía globalizada -o bien del capitalismo sin fronteras, como lo presenta el Banco Mundial- reside en la fragmentación de nuestro mundo, lo que incide directamente en la autocomprensión del hombre y, por ello, pone sobre la mesa de nuevo, y en formas inéditas, el problema de la identidad. Éste tiene su origen en la pérdida de los límites de la acción humana, derivados del fenómeno de la mundialización, que permite la expansión a escala planetaria de una determinada cultura local, que, a consecuencia de ello, se convierte en hegemónica.

Por su parte, tal proceso tiende a dejar a la intemperie a aquellas culturas locales que hasta ese momento habían conseguido protegerse gracias a la existencia de algún tipo de frontera. En esto reside el fundamento último del problema identitario: la mundialización, en cuanto explosión de las barreras culturales, pone al descubierto aquellos conflictos que sufre toda sociedad, al mismo tiempo que amenaza las identidades históricas al hacer patente la propia relatividad de éstas. Pero, ¿quées y qué no es identidad? La identidad, ¿precede a la razón ${ }^{9}$, o quizá debe antes ajustar las cuentas con ésta? El universalismo, bandera de las democracias liberales occidentales, y referencia para el mundo entero, ha entrado en abiertos conflictos con otros universalismos, por ejemplo con el islámico. Sucede así que los países menos desarrollados, de los que proceden los flujos migratorios, oponen dura resistencia a la pretensión de universalidad de los derechos del hombre, porque los juzgan el caballo de Troya con el que Occidente pretendería perpetuar con otros medios la propia dominación. Como es comprensible, también ésta es una profunda diferencia de las migraciones actuales con respecto a las dehace poco, un elemento que aún no ha merecido la adecuada atención de los especialistas en estos trabajos.

Todo lo anterior, me introduce en el tema central de este escrito, un tema que puedo ordenar sirviéndome de los tres interrogantes siguientes. Tomada conciencia de que nuestras sociedades tienden a ser sociedades de inmigra-

8 C. Geertz (1999), Mondo globale, mondi locali, Bolonia, II Mulino.

9 Así en un importante ensayo de A. SeN (2000), en La ricchezza della ragione, Bolonia, II Mulino. 
ción y emigración, ¿cómo configurar la relación entre multiculturalidad e identidad? Se puede decir, ¿hasta qué punto puedey debe avanzar una política de identidad (politics of identity) si se quiere, como supongo que cada cual quiere, que la pluralidad de las culturas presentes en un país resulte compatiblecon un orden social garante de la paz social y de las razones dela libertad? Segundo, reconociendo que la distancia creciente entre ciudadanía económicay ciudadanía socio-política ${ }^{10}$ del inmigrado ha llegado hoy a ser tan grande que ya no se puede asegurar la dignidad de la persona humana, ¿qué hacer para resolver la actual divergencia entre inclusión económica del inmigrado en el mercado de trabajo y en el sistema productivo del país de acogida, y exclusión de los derechos sociales y políticos? Tercero, si específicas razones de principio, además de prácticas, desaconsejan reediciones, más o menos puestas al día, sea del modelo asimilacionista de tipo francés, que tiende a hacer del diferente uno de nosotros, sea del modelo de la marginalización de los emigrados, es decir de su a partheid, sea incluso del modelo de autogobierno de las minorías, esto es el modelo de la balcanización de la sociedad, no queda otra que la vía de la integración en la sociedad de acogida de los recién llegados. Pero, ¿qué modelo de integración es el que se pretende?

En lo que sigue, tras una breve ilustración de las diferencias más significativas entre los movimientos migratorios de hoy y los de ayer, intentaré ofrecer una respuesta a los interrogantes recién planteados. No me ocuparé, sin embargo, de discutir ni las dimensiones del fenómeno migratorio ni su dinámica evolutiva. Sobre ambas cuestiones, ciertamente relevantes, la literatura existente es abundante y aceptable. Mientras remito para esta cuestión a los trabajos presentados en la reciente conferencia organizada, en Milán, por la Agencia Romana para el Jubileo ${ }^{11}$, me importa observar que hasta que no sea resuelta la espinosa cuestión referida a la elección del modelo de integración, no se logrará nunca dar un paso más allá de la disonancia cognitiva de buena parte de nuestra población: una disonancia por la cual al inmigrado se le busca y se la aprecia en tanto éste ocupa el lugar de trabajo donde contribuye a producir riqueza, y se le aparta y humilla una vez que ha salido de aquél. ¿Cómo decir que el ideal que algunos cultivan es un orden socio-político en el que los inmigrados sean "visibles" a los ojos de los residentes mientras actúan en el mercado de trabajo, sobre todo el

10 Vid. M. Colasanto y M. Ambrosinı (eds.) (1993), L'integrazione invisibile, Milán, Vita e Pensiero.

11 Agenzia Romana per IL Giubileo (2000), Migrazioni, mercato del lavoro e sviluppo economico, Milán, 2 vol; véase también la amplísima bibliografía allí contenida. 
irregular, para desaparecer de la vista y, por tanto, no resultar ya dignos de atención en cuanto ciudadanos, apenas esos inmigrados entran en otras esferas de la vida? Llama la atención poderosamente que atentos observadores, y hasta perspicaces estudiosos, no perciban la insostenibilidad de semejante contradicción pragmática y, sobre todo, el peligro para la paz social que tiene tal modo dicotómico de razonar.

\section{La cuestión migratoria hoy}

Los movimientos de personas de un país a otro o de una región a otra no habían conocido la intensidad y el carácter problemático de la época en que vivimos. Y aunque es cierto que el fenómeno migratorio es tan antiguo como la misma humanidad, no se puede negar, ciertamente, que el fenómeno en cuestión está asumiendo, en el curso de los últimos decenios y, sobre todo, tras la caída del muro de Berlín, características y tendencias totalmente nuevas. Conviene que nos paremos aquí en dos cuestiones.

La primera, relativa a la desconcertante paradoja de esta fase histórica: la mundialización económica, mientras acelera y magnifica la libertad de transferencia de bienes y de capitales, parece obstaculizar, de manera explícita y mucho más frecuentemente implícita, los movimientos de personas, poniendo en peligro el disfrute de aquel derecho del hombre-reconocido por todos- que es la libertad de movimiento. En otras palabras, en una época como la actual en que la cultura de mercado se va generalizando y va entrando en todos los dominios de la vida en común, debiera parecer normal ver en el fenómeno migratorio un recurso para formas más avanzadas de progreso humano. $Y$, contrariamente, cuando aquella misma cultura de mercado viene aplicada a los movimientos de personas, los términos que más afluyen son: expulsión, racionalización de entradas, permisos especiales. No es difícil, por supuesto, descubrir la raíz de tal disparidad de actitudes. Los impedimentos y obstáculos para los movimientos de las personas no se aplican a todos los inmigrantes indiferentemente, sino sólo a aquellos que, procediendo de ciertas áreas geográficas, son portadores de necesidades específicas. Se trata de una manifestación típica del llamado "síndrome de J ohannesburgo": los "ricos" deben comenzar a defenderse de los "pobres" dirigiendo u obstaculizando sus movimientos. Una nueva retórica cultural se va difundiendo de esta forma: los inmigrantes son responsables de la crisis social, de nuevos miedos colectivos y de serias amenazas a la salvaguarda de las identidades nacionales. 
La segunda cuestión que el nuevo fenómeno migratorio suscita es la definición del concepto de pertenencia: quién puede ser considerado miembro de una determinada comunidad política y quién está excluido. Como recuerda $\mathrm{Eco}^{12}$, a diferencia de la civilización griega fundada sobre la polis, que remite a una etnia de confines móviles, la mentalidad latina está obsesionada por la noción de frontera: Rómulo traza un límite y mata a su hermano porque no lo respeta. El derecho romano nace del territorio, esto es, de un espacio marcado por un límite. Sólo quien pertenece a ese espacio, es parte de la civitas. "El problema-escribe Eco- es que en el próximo milenio Europa será un continente multirracial o si se prefiere multicolor. Estoy convencido de que esta confrontación o desencuentro de culturas tendrá precios dolorosos que pagar, que serán inevitables y durarán mucho tiempo... Hubo un patricio romano que no aceptaba que llegasen a ser cives romanos también los galos, los sármatas o los judíos, como san Pablo, y que pudiese acceder a la sede imperial un africano, como finalmente sucedió. De este patricio nos hemos olvidado, ha sido barrido de la Historia". Estoy persuadido de que la pertenencia constituye hoy un problema más urgente a resolver que aquel, ciertamente más antiguo, de la justicia distributiva. Sin embargo, sólo después de haber identificado quién es titular de derechos específicos se puede pasar a discutir sobre la aplicación de los principios dejusticia. En este sentido, la solución de la cuestión migratoria constituye un prius respecto a la vasta problemática de la justicia social. Pero, ¿en qué se concreta la cuestión de la pertenencia referida a la figura del homo migrans? No tanto en negar al inmigrante ciertas ayudas o el acceso a determinados servicios, cuanto en negar su dignidad y autoestima, lo que ocurre siempre que se le somete a políticas sistemáticas de humillación. Según Walzer hoy está reapareciendo en nuestras sociedades avanzadas la diferenciación de la antigua Atenas entre los ciudadanos de pleno derecho y los metecos, trabajadores extranjeros tolerados en cuanto tales, pero desprovistos de derechos cívicos. Propiamente esto es la negación del principio de pertenencia ${ }^{13}$.

Aclarado esto, pasemos a considerar algunas novedades relevantes que el fenómeno de la mundialización va generando en los flujos migratorios. Una primera novedad es la percepción, hoy día extendida incluso entre los que no son expertos, de que en la época de la mundialización y de la nueva economía, los flujos migratorios están destinados a crecer por razones estructurales,

12 U. Eco, "prefacio" a A. Calabrò (ed.) (2001), Frontiere, en II Sole-24 Ore, Milán.

13 Citado en M. Ambrosinı (2000), Utili invasori, Franco Angeli, Milán. 
que tienen bien poco que ver con aquéllas que tradicionalmente han explicado las migraciones en el pasado. Dicho de otro modo, las nuevas tecnologías infotelemáticas y la creación de un mercado de trabajo global, dos de entre las más relevantes res novae que definen la nueva economía, están provocando profundas transformaciones en los flujos migratorios internacionales, tanto por la mutación de los factores de atracción (pull), como por los de expulsión (push). Intentemos aclararlo. Más de un experto ha señalado algunos de los lazos que tienen en común las migraciones de hoy con los primeros movimientos decomienzos del siglo XIX. Dehecho, se recuerda que en ese siglo y hasta el estallido de la primera guerra mundial, cerca de 52 millones de europeos emigraron de sus países de origen, y de estos unos 34 millones eligieron los EE.UU. de América del Norte. El célebre Passenger Act, votado por el Parlamento de Westminster en 1803, animaba la emigración hacia las excolonias inglesas. Hasta 1860 , el $66 \%$ de los emigrados europeos hacia América y Oceanía procedían de Gran Bretaña y otro 32\% era originario de Alemania. Esta última llegó a ser, después de 1880, importadora neta de fuerza de trabajo. Informaciones de este tipo han de tenerse correctamente en cuenta para no agigantar más allá de lo debido las diferencias entre la situación de entonces y la de ahora, pero igualmente se deben reconocer los grandes elementos de discontinuidad. Uno de estos es la aparición de las nuevas tecnologías en los procesos productivos: mientras que han convertido más cercanos entre sí a países espacialmente distantes, no ha eliminado del todo, antes bien ha ampliado, las distancias culturales. No hay quien no vea que el nexo entre universos culturales y empleo de nuevas tecnologías va a ser de central importancia en los procesos de integración social. Mientras se pide al inmigrado desarrollar tareas simplemente rutinarias o cumplir faenas puramente mecánicas, la distancia cultural entre mundos de procedencia y de llegada no se hace sentir. No es así, sin embargo, cuando para insertarse provechosamente en la actividad de trabajo, el inmigrado debe adquirir, haciéndolos propios, esquemas lógico-organizativos propios de una matriz cultural bien definida ${ }^{14}$. En realidad la inserción del inmigrado en sociedades tecnológicamente avanzadas plantea problemas mucho más delicados que los del pasado, incluso el más reciente.

Un segundo elemento de profunda diferenciación entre las migraciones de hoy y las de ayer es el siguiente: no parece apoyada en los hechos la tesis, de

14 A. Fallla e M. Lombardi (eds.) (1993), Immigrazione, lavoro e tecnologia, Milán, Fondazione IBM - Etas Libri. 
moda hasta los años 80 , según la que el instrumento más eficaz para disminuir la presión migratoria sería acrecentar las posibilidades laborales en los países en vías de desarrollo. Si tal argumento fuese correcto, bastaría entonces sugerir a estos países la adopción de técnicas de alta intensidad de trabajo para parar, o al menos reducir, la entidad de los flujos migratorios. Pero las cosas no se plantean en estos términos. En primer lugar, porque en los países en vías de desarrollo la emigración, más que representar una alternativa al proceso de desarrollo, constituye hoy un medio para hacer arrancar ese proceso. Esto se debe a que los emigrados logran hacer llegar recursos financieros directamente a manos de potenciales utilizadores sin pasar por la mediación del Estado o de las agencias públicas; por otro lado, la emigración constituye el modo más rápido, y menos costoso para un país pobre, deentrar en posesión de las habilidades y de los conocimientos requeridos por los nuevos paradigmas tecnológicos. En segundo lugar, porque durante los primeros estadios del proceso de desarrollo se generan incentivos específicos para la emigración. De hecho, el aumento de las desigualdades socioeconómicas que siempre acompaña a las fases iniciales de crecimiento empuja a segmentos crecientes de población a tomar el camino de la emigración. Además, como la new economics of migration ha ilustrado claramente, hay que prestar más atención a la familia que al individuo.

En una óptica de este tipo, la decisión de emigrar es interpretada como una estrategia de diversificación de los riesgos: algunos miembros de la familia emigran, para permitir a aquellos que se quedan en el país mejores perspectivas de vida. En definitiva, sería vana la ilusión de pensar en parar los flujos migratorios, al menos en el corto o medio plazo, apostando simplemente por el lanzamiento de procesos de desarrollo en los países generadores de los mismos. El desarrollo es ciertamente necesario, pero no suficiente, para neutralizar la presión migratoria en el tiempo breve o medio.

A la luz de cuanto precede, nos podemos dar cuenta del sentimiento de miedo que acongoja a nuestras poblaciones europeas, y a la italiana en particular ${ }^{15}$ : el miedo estriba en que nuestras sociedades se muestran incapaces de gobernar flujos crecientes de inmigrantes portadores de culturas muy diferentes de las nuestras; frente al temor, la actitud predominante

15 Véase la segunda encuesta sobre "Inmigración y ciudadanía en Europa", a cargo de la Fundación NordEst, Venecia 2001, en la que se observa que Italia es el país europeo donde es más fuerte el miedo a que los extranjeros traigan desorden e inseguridad $(42,8 \%$ contra el $35,8 \%$ en Francia y el $32 \%$ en el Reino Unido). Sin embargo Italia es el país europeo donde menor es la presencia de extranjeros. 
es la cerrazón, "esconder la cabeza bajo las alas", para no afrontar de modo creativo un problema de alcance transcendental.

\section{Cuatro modelos de integración del inmigrado}

Antes de adelantar una propuesta específica orientada a afrontar, y posiblemente resolver, los interrogantes planteados en la introducción, me parece oportuno dedicar algunas palabras al abanico de aproximaciones que la filosofía moral y la teoría política han puesto en circulación, en el curso del último decenio, sobre la cuestión de que se trata. Según Galeotti ${ }^{16}$ es posible reagrupar la vasta literatura sobre el tema en torno a cuatro posiciones teóricas, cada una de las cuales puede acoger, en su propio interior, cierto número de variantes.

La primera de éstas es la autodefensa intransigente del orden social de cuño liberal. Según esta posición, el multiculturalismo, al que me referiré más adelante, constituiría el factor de potencial destrucción de los valores fundadores de las sociedades occidentales, entendiendo por tal la sociedad nacida con la Revolución francesa. Una inmigración indiscriminada acabaría por constituir una amenaza para el patrimonio cultural de Europa, si se llegase a afirmar que el reconocimiento de las minorías étnicas y de su identidad debe ensancharse hasta abarcar la esfera pública. Sin embargo, la democracia liberal, justo porque ofrece a to dos, autóctonos e integrados, las mismas oportunidades deja que cada uno de los individuos aislados sea libre de asociarse privadamente para tutelar sus intereses y para dar cauce a sus propias prácticas vitales, religiosas u otras. Lo que viene a significar que las instituciones públicas del país de acogida, mientras deben estar dispuestas a reconocer $y$, por tanto a tutelar, los intereses de los inmigrados, no deben comprometerse en el reconocimiento de su identidad.

Para evitar equívocos conviene precisar que la diferencia esencial entre reconocimiento de los intereses y reconocimiento de las identidades estriba en que el primer tipo de reconocimiento puede limitarse sólo a la esfera privada, mientras el segundo postula necesariamente la referencia a la esfera pública. La lucha por el reconocimiento de las identidades de los individuos y de los grupos plantea, por esta causa, problemas más delicados y difíciles de resolver que la lucha por el reconocimiento de sus intereses. Los conflic-

16 A.E. Galeotti (1999), Multiculturalismo, Nápoles, Liguori. 
tos de este último tipo, con todo, son negociables, sobre todo desde que la institución mercado fue creada durante el Renacimiento, justamente para resolverlos. Los conflictos identitarios, según la expresión de A Pizzorno, no son objeto de negociación, es decir no se les puede aplicar los métodos usados en el mercado. Son resueltos, en cierta manera, provocando un perjuicio a la sostenibilidad misma de las sociedades: no sería, con todo, estable una sociedad formada por identidades colectivas irreconciliables entre sí, en la que cada una de ellas reivindicase un reconocimiento público.

Escribe Sartori, uno de los autores más representativos entre los que se reconocen en la tesis de la autodefensa intransigente del orden liberal: "La verdad obvia es, pues, que la integración es posible a los integrables y, por tanto, que una ciudadanía concedida a inmigrados inintegrables no lleva a integración sino a desintegración”, y más adelante: “...el pluralismo no refuerza, si acaso suaviza, las identidades con las que se encuentra, mientras el multiculturalismo configura la partición de la comunidad pluralista en subconjuntos de comunidades cerradas y homogéneas"17. En la misma longitud de onda se mueve el historiador norteamericano Schlesinger ${ }^{18}$ cuando anota que el multiculturalismo es la causa principal de la "desunión de América" y de su déficit de capital social. Provocando una destrucción del tejido político tradicional en lógicas de pertenencia étnica o social, el multiculturalismo está siendo responsable de la decadencia del "espíritu público" en los Estados Unidos de Norteamérica.

La segunda posición es la de los defensores de la sociedad intercultural. Según estos es necesario llegar a una revisión del orden social liberal, que, mientras conserva inalterado el núcleo constitutivo de sus principios, haga a este orden capaz de tomar en consideración las demandas identitarias de las minorías y ello a fin de asegurar a todas las personas una inclusión equitativa. El argumento, en resumen, es el siguiente. Es cierto que los principios y las instituciones de la democracia liberal (neutralidad, imparcialidad, universalidad de los derechos humanos, libertad personal, justicia

17 G. SARTORI (2000), Pluralismo, multiculturalismo e estranei, Milán, Rizzoli; los textos citados en p. 99 y p. 111. Para una defensa cuidadosa de la primacía axiológica de individuo y para una clara toma de posición contra los peligros del multiculturalismo identitario, véase $\mathrm{E}$. Vitale (2000), Liberalismo e multiculturalismo. Una sfida per il pensiero democratico, Roma, Laterza. Para una crítica de la tesis expuesta por Sartori, véase F. Dossetto, "I molti modi di leggere il multiculturalismo": II Mulino 2 (2001), pp. 345-352.

18 A. Schlesinger (1991), The disuniting of America. Reflections on a multicultural society, Princeton, W. Norton. 
social) se aplican y valen para todos, inmigrados y no, como siempre ha afirmado la tradición jacobino-republicana; pero es asimismo cierto que la extensión de todos los derechos no genera, por sí misma, el pleno acceso a la ciudadanía si algunos sujetos, en nuestro caso los inmigrados, no tienen la capacidad efectiva de disfrutar de esos derechos a través de su identidad cultural. En su Mensaje para la J ornada Mundial de la Paz (1 de enero de 2001), con el título "Diálogo entre las culturas para una civilización del amor y de la paz", Juan Pablo II después de afirmar que "ser humano significa necesariamente existir en una determinada cultura", continúa: "asistimos con creciente inquietud al polémico afirmarse de algunas identidades culturales contra otras. Este fenómeno... hace penosa la condición de algunas minorías que se encuentran viviendo en el contexto de mayorías culturales diversas, inclinadas a actitudes y comportamientos hostiles y racistas" 19 .

Considérese el caso, cada día más frecuente, de la así llamada discriminación estructural, debida a la diversidad de las categorías cognitivas del inmigrado y del residente. No se trata de una discriminación deliberada, y menos aún reflejada en la legislación, como es con las formas clásicas de discriminación, o lo ha sido frecuentemente, pero la discriminación estructural limita enormemente la real capacidad de integración del extranjero procedente de un universo cultural diferente del propio del país de acogida. De hecho, las instituciones principales de una sociedad se apoyan siempre sobre hábitos, prácticas y reglas de comportamiento que son resultado de una precisa tradición cultural. Un ejemplo para todos: es hoy frecuente y usual, en muchos lugares del mundo occidental, la práctica de entrevistas y de tests de actitudes para las contrataciones laborales. Contrariamente a cuanto muchos piensan, no se trata de una práctica culturalmente neutral; en realidad, lo que el test verifica es la capacidad de adaptación, de parte del sujeto, a un particular modo de realizar la organización del trabajo, un modo que es a su vez el resultado de un específico horizonte cultural. Piénsese, por ejemplo, en el diverso significado de la organización del trabajo en el fordtaylorismo, en el toyotismo, en la empresa cooperativa o en una organización sin lucro. No debe entonces sorprender si, junto a la insuficiente cualificación profesional, la discriminación estructural representa la segunda gran causa de impedimento para la integración del inmigrado. En situaciones de este tipo, sirve de poco garantizar a todos las mismas oportunidades, si se sabe que estas últimas no pueden transformarse en las mismas capacidades

19 Nn. 5 y 8 respectivamente. 
(capabilities en el sentido de Sen); ni basta asegurar el acceso a los cursos de lengua para extranjeros, porque lo que es problema no es el desconocimiento lingüístico por sí mismo, sino la posesión de determinadas categorías de pensamiento y la familiaridad con cierto modo de pensar, típicas de una determinada lengua ${ }^{20}$. Como dice oportunamente Galeotti, el reconocimiento público de las identidades y, para ello, la predisposición de acciones y providencias adecuadas por parte de las instituciones, es defendido por los partidarios de esa posición, en el plano de la justicia, para consentir que a todos afecte el principio liberal universal, es decir que la no discriminación pueda ser realmente aplicada. Téngase en cuenta que esto no significa que siempre y en todo caso las demandas identitarias deban ser acogidas, ni a fortiori que deban serlo en sus propios términos: en la próxima sección me detendré a explicar un preciso criterio de selección de tales demandas. La perspectiva intercultural, que hace suya la idea de la convivialidad de las diferencias, considera legítima, en nombre del principio de justicia, la búsqueda del reconocimiento de las culturas particulares en el ámbito de la esfera pública. Interesa observar que la noción de esfera pública es entendida aquí como espacio social en el que los componentes de una sociedad discuten cuestiones de interés común, formando sobre estas cuestiones públicas opiniones a partir de la confrontación de los respectivos juicios de valor.

La tercera posición es la del "multiculturalismo pluralista", como la llama Kymlicka ${ }^{21}$. Se trata de una posición que lleva a reinterpretar, y no simplemente revisar, el estatuto de la democracia liberal para hacerla capaz de acoger una especial y nueva categoría de derechos: los derechos culturales específicos de los grupos minoritarios, pensados como baluarte contra las pretensiones asimilacionistas de la mayoría. La novedad de una posición de ese estilo, ciertamente no de poca importancia, es la de legitimar la demanda de derechos culturales colectivos, cuyos destinatarios serían los grupos de

20 Puede ser interesante recordar lo que, a propósito de las implicaciones políticas de la asimilación lingüística, escribía Antonio Nebrija, célebre lingüista español del siglo XV, en la introducción a la primera gramática escrita sobre una lengua europea: "La lengua ha sido siempre compañera del imperio"; cita en L. MAFFI, "La lingua, una risorsa per la natura": Pluriverso, no 3 (2001) 31.

21 W. Kymlicka, "Associazioni etniche e cittadinanza democratica": Ricerca 3 (2000). Original inglés en "Freedom of association", 1999. Este autor distingue dos tipos de sociedades multiculturales: las multinacionales, en las que la diversidad de identidades deriva del englobamiento de entidades culturales preexistentes en el interior del nuevo Estado; y las poliétnicas, en las que la diversidad cultural es el resultado de procesos migratorios de masa. 
individuos en cuanto tales y a cuyo ejercicio proveería el grupo a través, obviamente, de sus representantes. Para comprender la distancia de esta posición del estatuto axiológico liberal ha de tenerse presente que este último no admite la posibilidad de derechos colectivos: sólo el individuo, de hecho, es portador de derechos. La idea de fondo que encontramos en la base del multiculturalismo pluralista es que los inmigrados desean ciertamente integrarse en la sociedad que les acoge, pero "reclaman" que las instituciones sean adaptadas a sus prácticas y a sus identidades. Esto es lo mismo que decir que las peticiones de los inmigrados implican la renegociación de los términos de la integración, para permitir que aquellos expresen sus particularidades en el interior de las instituciones del país de acogida. Valgan aquí un par de ejemplos. Los currículos escolares existentes son reformados para consentir un cierto espacio a la aportación de las culturas de las minorías étnicas; lo que es como decir que se deben integrar en la cultura del país de acogida "piezas" significativas de las culturas recibidas. Sólo así, de hecho, sellegaría a dar valor público, y por tanto pleno respeto, a las identidades particulares. Otro ejemplo es el que se refiere a la adaptación institucional de las reglas del mercado de trabajo: de la revisión de los módulos laborales a las reglas de vestido, a la adaptación de los lugares de trabajo y otras muchas cosas.

Como se comprende, las políticas públicas que deben ser puestas en práctica para hacer concreta la acogida de esta posición no se limitan a proveer a los inmigrados de los "instrumentos" que necesitan para integrarse, sino que empujan hasta abrir a los inmigrados aquellas instituciones a las que ellos no tendrían, de otra forma, acceso por medio de sus características étnicas. Por ejemplo, la apertura de los servicios públicos especiales para los inmigrantes en los sectores esenciales de la sociedad, como son escuela, vivienda, sanidad, legislación, es útil para preservar y desarrollar las identidades de las diferentes minorías. Es evidente que tampoco para el multiculturalismo pluralista son, en ningún caso, aceptables aquellas políticas y aquellos procedimientos que conculcan, en alguna medida, los derechos humanos fundamentales: mutilaciones sexuales de las niñas, reconocimiento legal de matrimonios "arreglados", divorcios talaq, marco legal de las reglas dela familia musulmana, etc.; en estesentido, esta forma demulticulturalismo sigue en el interior, aunque sea en los bordes, del círculo liberal-democrático.

Por último, la cuarta posición teórica es la que han hecho suya los liberales comunitaristas americanos según quienes, frente a la postulada irreconciliabilidad entre multiculturalismo y teoría liberal-democrática, es necesario optar a favor de la primera alternativa. Nacido en o posición al neocontractua- 
lismo de J ohn Rawls, juzgado demasiado individualista, el comunitarismo se desarrolla a través de direcciones distintas, desde la de los "antiliberales" de matriz neopositiva, R. Rorty, C. Taylor, M. Walzer, E. Sandel, a la neoaristotélica de A. MacIntyre y de A. Etzioni, cuyo objetivo es superar la separación entre moral y política ${ }^{22}$. La tesis central de la posición comunitarista es que el factor cultural múltiple presente en una sociedad debe ser simplemente reconocido como tal y todas las diferencias mantenidas, aun cuando a veces no sea con formas iguales. Esto es coherente con lo que afirman los comunitaristas: los valores y los principios no pueden aspirar al estatuto de objetividad y de universalidad, pues se enraízan (embedded) en las diferentes comunidades humanas particulares. De otra forma, una vez aceptado el principio del relativismo cultural, no se hace otra cosa que levantar acta de la pluralidad de las culturas. Puesto que las culturas son incomparables entre sí y no tienen fundamento objetivo, son todas iguales. De ahí surge la legitimación de la expresión "lucha por el reconocimiento", utilizada por los comunitaristas, una lucha que reclama para los varios grupos étnicos presentes en la sociedad formas de autogobierno expresivas de las varias identidades culturales y, por eso, se arriesga a una deriva aislacionista, es decir a una balcanización de la sociedad.

No es difícil captar los elementos de enorme fragilidad de tales posiciones. En primer lugar, es ciertamente verdadero que el contacto y la confrontación entre diversas culturas lleva a éstas a modificarse recíprocamente, provocando influencias y cambios mutuos. Pero ello supone, si se quiere que el éxito sea el deseable, que los resultad os satisfagan la condición de equivalencia o de paridad ética entre las culturas. En caso contrario, el riesgo es que "mezclando" entre sí culturas que no son combinables se obtengan resultados perversos. Pues bien, en el momento mismo en que se plantea la cuestión de la equivalencia entre las culturas surge le problema de definir qué núcleo de valores y principios debe servir como canon para medir las mismas. Sobre este punto, los defensores del multiculturalismo comunitarista no pueden hacer otra cosa que callar, una vez que se ha afirmado que las culturas son incomparables. Para evitar equívocos hay que cuidar no confundir el relativismo cultural con la relatividad, que es el reconocimiento de las variaciones culturales. El relativismo, a diferencia de la segunda, sostiene la imposibili-

22 Para un eficaz encuadramiento de la filosofía y de la epistemología comunitarista véase A.M. Petroni, "Comunitarismo e liberalismo": Keiron 6 (2001), así como el número monográfico sobre "Le forme del comunitarismo": La prospettiva comunitaria 2 (1999), en particular los ensayos de A. Ansaloni, L. Pesenti e L. Lannae. 
dad de recomponer, de algún modo, la pluralidad en unidad y por tanto la única posibilidad, para el relativisimo, es la tolerancia que, en buena medida, significa que por el solo hecho de existir toda cultura está justificada.

Existe además otra gran dificultad para acoger la propuesta del comunitarismo filosófico. Según éste los valores no vuelan con sus propias alas y, por esto, se exige bastante más que la mera aceptación social de los valores presentes en una determinada sociedad para guiar el comportamiento de sus miembros; lo que se exige además es la capacidad de los ciudadanos de cooperar activamente para reforzar las redes de la vida asociativa, teniendo en cuenta el hecho de que el bien social se confía mucho más a la "voz moral" que a la fuerza coercitiva del Estado. Para los comunitaristas la moral voice es una forma peculiar de motivación que es expresión de la comunidad a la que el sujeto pertenece. Sería, pues, la "voz moral culpabilizadora" (convicting moral voice) la que garantizaría el orden social sin tener que recurrir, salvo en casos extremos, a la fuerza del Estado. Ahora bien, es cierto que la identidad social representa un papel más bien importante en el comportamiento de las personas y, por tanto, hace bien la filosofía comunitarista en insistir en que la acción individual no puede ser comprendida plenamente si se la abstrae de la trama de relaciones que vinculan a la persona con un determinado contexto. Pero esto, de ninguna manera, puede legitimar a aquellas pertenencias que tienden a excluir otras pertenencias ( piénsese en muchos casos, cada día más frecuentes, en que una misma persona pertenece a varias comunidades o grupos de referencia); ni puede justificar una pertenencia no elegida, es decir, una pertenencia no sometida al examen de la razón. Anulando la libertad individual en la lógica de la identidad comunitaria, el comunitarismo acaba negando 0 , al menos, haciendo particularmente difícil el ejercicio del derecho de cada uno a separarse de la comunidad de referencia en el momento en que ésta no corresponda ya al propio sistema de valores. Podemos pensar en el caso de quien, por una razón u otra, quisiera cortar su vínculo de pertenencia religiosa.

Como oportunamente aclara Sen ${ }^{23}$, el problema a resolver a este propósito es doble. Primero, la identidad social, ¿es algo que el individuo "elige" por sí o quizá algo que le viene impuesto y por quién? Segundo, incluso prescindiendo de la primera pregunta, ¿cuánta racionalidad entra en la definición de

23 A. Sen (2000), "La ragione prima dell'identità", en La ricchezza della ragione, Bolonia, Il Mulino. Véase también el estimulante ensayo de R. HARDIN (1995), One for all: the logic of group conflict, Princeton, Princeton University Press. 
identidad social? De otra forma, ¿cuál y cuánto espacio reservar a la razón como componente de la identidad? La toma de posición de Sen a este respecto es neta: "Existe un papel significativo de la razón en la elección de la identidad y existen sólidas bases para rechazar el presupuesto comunitarista para quienes la identidad social es una cuestión de 'descubrimiento' antes que un proceso de elección racional y libre... Tenemos motivos para dudar sobre la separación operada entre epistemología y ética que realizan los defensores del comunitarismo más radical y sobre la tendencia, próxima a aquella, que trata a las diversas culturas como islas cognitivas o morales"24. Esto significa que el fundamento de la relación social es la subjetividad del individuo, relación que es edificada 0 , en su caso, reconstruida a partir de sujetos que son capaces y libres para elegir. Fundamentar la socialidad humana en una especie de gran sujeto, un ente primitivo, sea la comunidad, la clase, el Estado u otro cualquiera, no puede pretender una eticidad avanzada, pues dicha sociabilidad supone, siempre y en cualquier sitio, la libertad de elección de parte del sujeto, a no ser que se defiendan formas, más o menos enmascaradas, de reificación de la comunidad.

En definitiva, el modo comunitarista de tratar culturas diversas como "islas cognitivas", no confrontables ni comparables entre sí y, por ello, incomunicables, hace imposible, a pesar de las apariencias, el diálogo intercultural. Este problema es zanjado expeditivamente por los pensadores del multiculturalismo comunitarista, quienes no parecen darse cuenta de que la "lucha por el reconocimiento" de las diversidades constituiría una buena hipótesis de trabajo a condición de que ésta fuese a favor del reconocimiento de la verdad presente, en mayor o menor medida, en toda cultura y no primeramente la lucha por la diversidad en cuanto tal. Mantengo mi acuerdo con Heller cuando escribe: “El multiculturalismo es la utopía de unas mismas oportunidades de vida para todas las comunidades, directa e indirectamente. Una utopía, sin embargo, que garantiza iguales oportunidades de vida es incompleta hasta que la libertad como valor superior no sea integrada en la misma. Ésta puede serlo con tal que la incorporación y el abandono decada cultura, natural o elegida, sea, en un principio, y permanezca como un acto de libre elección... No se pueden integrar los valores de la libertad y de la vida y, al mismo tiempo, negar a los individuos la posibilidad de que ellos mismos libremente decidan qué es mejor para ellos. En el caso de que las decisiones de al gunos fueran perjudicadas o sujetas a preferencias

24 A. Sen, op.cit, p. 31. 
impersonales, la norma del multiculturalismo llega a ser instrumento de abuso e imposición" 25 . En efecto, la contradicción que el multiculturalismo no llega a resolver estriba en que niega la existencia y cognoscibilidad de verdades universales $y$, a la vez, impone el principio de tolerancia. Pero una de dos: o se afirma que no hay principios éticos transculturales, y entonces también la no tolerancia debe ser aceptada; o bien, se pretende proponer el principio de tolerancia como verdad universal, y entonces se deberenunciar a la premisa de la incapacidad universal para conocer valores universales.

En el esquema clasificatorio aquí esbozado, la propuesta que ahora voy a desarrollar puede remitirse, con algunas cualificaciones importantes, a la segunda de las posiciones teóricas consideradas, la de la interculturalidad. Está claro, como documenta suficientemente Martiniello ${ }^{26}$, que hay una diferencia sensible entre los modelos abstractos de gestión de la diversidad de identidades y las prácticas sociopolíticas: en la realidad, se verifica cierta convergencia, aunque no uniformidad, entre las prescripciones que derivan delos diferentes modelos. Esto es cierto y, hasta cierto punto, consuela, pero nadie puede negar la importancia de discutir las diversidades teóricas entre un modelo y otro.

\section{El modelo de integración intercultural}

¿A qué principios básicos debe satisfacer un modelo de integración que haga propia la perspectiva intercultural, una perspectiva que, como he recordado más arriba, rechaza tomar en consideración sólo las diferencias que separan a los inmigrados de los autóctonos, lo que llevaría a formas más o menos acentuadas de balcanización de la sociedad, y rechaza una asimilación más o menos explícita y forzada, que negase la existencia de diferencias significativas entre unos y otros? Dicho de otro modo, ¿qué principios deben fundar una posición que asegure a todos la satisfacción de los derechos fundamentales del hombre y, al mismo tiempo, garantice un espacio público en el que los sujetos portadores de una identidad cultural diversa de aquella del país de acogida puedan confrontar sus respectivas posiciones de forma pacífica y, sobre todo, puedan llegar al consenso en torno a los límites dentro

25 A. Heller, "The many faces of multiculturalism" en R. Banbck, R. Heller, A. Zolberg (eds.) (1996), The Challenge of Diversity. Integration and Pluralism in Societies of Immigration, Viena, Aldeishot, Avebury; texto cit., p.28

26 M. Martiniello, “Gestire la diversità culturale e identitaria”: Il Mulino 5 (2000). 
de los cuales éste pueda mantenerse? Indico cinco principios, y advierto enseguida que el contexto en el que deben aplicarse, a mi juicio, tales principios es el de los Estados uninacionales, como Gran Bretaña, Francia, Italia, y no en el contexto de Estados multinacionales, del tipo de España, Canadá, Suiza o Bélgica. Como es fácil comprender, para esta última categoría de países, el modelo que llamo de integración intercultural está sometido a algunas adaptaciones.

El primer principio es la primacía de la persona sobre el Estado y sobre la comunidad. En relación con lo primero no es necesario gastar palabras, pues se trata de una adquisición hoy consolidada, al menos en nuestras sociedades occidentales. Conviene, sin embargo, decir algo sobre la otra relación, la de persona y comunidad. Escribe Sandel, agudo exponente del comunitarismo radical, a propósito de la identidad comunitaria concebida como al go que pertenece a la autorrealización del sujeto y no a su libre elección: "La comunidad dice no sólo lo que estos tienen en cuanto ciudadanos, sino también lo que son; una relación que no eligen, como sucede en las asociaciones voluntarias, sino una atracción que descubren; no sólo un atributo sino un elemento constitutivo de su propia identidad"27. Es como decir que la comunidad, y por tanto la identidad, aparece "primero" que la persona que elige, y por tanto es "anterior" a la razón que guía la elección.

No hace falta mucho esfuerzo para comprender por qué quien se reconoce en las posiciones de la filosofía personalista, magistralmente enunciadas en El hombre y el Estado de J acques Maritain, no puede aceptar una inversión del nexo entre persona y comunidad. Escribe Sen: "La persona que descubre que es judía debe siempre decidir cuánta importancia atribuye a esta identidad concreta que es confrontada con otras identidades concurrentes, de nacionalidad, de clase, de credo político, etc. Las opciones deben ser hechas también cuando está en presencia de descubrimientos"28. En buena medida es la subjetividad de la persona el fundamento dela relación comunitaria, que es edificada o reinventada a partir de los sujetos que son capaces y libres para elegir y por tanto capaces de asumir la responsabilidad del propio destino. Es cierto que el individuo aislado es pura abstracción y, como expondré en seguida, la identidad individual no puede prescindir de la trama de relaciones que une al individuo con la comunidad, pero el denominador

27 M. SAndel (1998), Liberalism and the limits of Justice, Cambridge, Cambridge University Press, p.150.

28 A. SEN, op. cit, p. 31. 
común colectivo no llega nunca a definir plenamente a cada persona, que es sin embargo siempre un conjunto de atributos únicos. Novak recuerda, a este propósito ${ }^{29}$, la célebre discusión entre Tomás de Aquino y los averroístas acerca de la negación por estos de la responsabilidad personal y de la capacidad de elección, para indicar una de las grandes dificultades que la filosofía islámica encuentra desde siempre para fundar una filosofía de la libertad. No basta, en fin, la "libertad de la necesidad" que equivale, en buena medida, a la libertad negativa en el sentido de l. Berlin. Así piensan en cambio los comunitaristas para los que el sujeto es libre en la medida en que se identifica con una comunidad, ya que así descubre la propia identidad, dado que ésta es, en la práctica, quien asegura al individuo la libertad de la necesidad. Pero, las comunidades, o bien se mueven en el respeto de los derechos del hombre o bien caen en formas más o menos marcadas de neotribalismo contra las que el pensamiento personalista no puede hacer otra cosa que enfrentarse con fuerza.

Al mismo tiempo, sin embargo, la libertad -éste es el segundo principiono es plenamente tal si no va más allá de la simple autodeterminación, "hacer lo que se quiere". Tal concepción es demasiado simple para que pueda ser compatible con el pensamiento personalista. De hecho la persona, a diferencia del individuo, es definida también por la cultura en que ha crecido y en la que elige reconocerse. Ciertamente, lo que es típico de la persona humana es la relacionalidad, que postula que el otro llegue a ser un tú. Si mi estar en relación con el otro obedece sólo a consideraciones de conveniencia, como la consecución del consenso o la resolución de conflictos, no saldré nunca de la "insociable sociabilidad" de que habla Kant. Ahora bien, aunque seré libre en el sentido de la autodeterminación, no lo seré en aquel otro más consistente de la autorrealización, desde el momento en que la libertad como autorrealización necesita de la relación con el otro como valor en sí mismo. Si es cierto que hoy nadie está dispuesto a disolver su "yo" en un "nosotros" cualquiera, es también cierto que la alternativa no puede ser el átomo social, como sostiene el pensamiento individualista, sino un "yo-persona" que no acepta desaparecer en ningún mecanismo, ni siquiera en el del mercado.

La plena realización de la identidad personal no puede por tanto limitarse al simple respeto de la libertad de los otros, como afirma la posición neoliberal para la que vivir en común es una opción. Sabemos, en efecto, que para cada uno de nosotros no es de ninguna manera así. La elección no está entre

29 M. NovaK (2000), Spezzare le catene della povertà, Macerata, Liberilibri, cap.VII. 
vivir en soledad o vivir en sociedad, sino entre vivir en una sociedad so metida a unas reglas 0 a otras. Es, por lo tanto inaceptable para un concepto hondo de libertad pensar en una individualidad que prescinda de la relación con el otro. He aquí porqué las culturas merecen tutela y reconocimiento también en el ámbito de la esfera pública. Si es cierto que la identidad personal nace dialógicamente como respuesta a nuestras relaciones con los otros, entonces una sociedad auténticamente respetuosa de las razones de la libertad no puede negar que la preservación de un contexto cultural seguro, esto es, no amenazado ni, menos aún, negado, constituye un bien primario sobre el que confluye el interés fundamental de cada uno. Si así ha de ser, conviene presionar para el reconocimiento público de las particularidades culturales.

El tercer principio es el de la neutralidad, no la indiferencia del Estado, en la confrontación de las culturas que son "sostenidas" por los que residen en él. Intentemos aclarar esto brevemente. Se trata de un hecho conocido, aunque frecuentemente discutido, que la modernidad ha erosionado, en el curso del tiempo, el fundamento relacional de los valores, que han acabado por adquirir una dimensión cada vez más privada, casi facultativa. Subjetivizando los valores, o bien haciéndolos retroceder en el ámbito de preferencias o gustos individuales, esta visión ha negado o disminuido la carga social que siempre tienen los valores. La visión relativista de la libertad, típica de la concepción liberal-indidualista, reduciendo la libertad a mero permisivismo privado, ha favorecido la confusión entre el Estado laico, esto es el Estado neutral en las relaciones de las diferentes culturas presentes en él, y el Estado indiferente, un Estado que se declara incapaz de elegir o de establecer diferencias entre culturas diversas. Si la neutralidad se refiere a la imparcialidad con que el Estado debe tratar a las diferentes identidades, el indiferentismo habla de la imposibilidad de fijar un orden entre diferentes instancias culturales puesto que no existe un criterio objetivo de elección. Es importante, a estos efectos, la célebre sentencia de la Corte Constitucional italiana en 1989: “El principio de laicidad, tal como emerge de la Constitución, implica no la indiferencia del Estado frente a las religiones, sino la garantía del Estado para la salvaguardia de la libertad de las religiones, en régimen de pluralismo cultural y religioso"; y, más adelante, afirma: "La actitud laica del Estado responde no a postulados ideologizados y abstractos de extrañeidad, hostilidad o confesionalidad, sino que se pone al servicio ${ }^{30}$ de las instancias concretas de la conciencia civil y religiosa de los ciudadanos". Es lo mismo

30 La cursiva es del autor. 
que decir que el Estado laico no puede ignorar presupuestos de valor que no toca a él producir, ya que se convertiría en Estado ético si los produjese él, pero sí que corresponde al Estado laico ser receptivo ante los diferentes sujetos de la sociedad civil portadores de cultura.

Como observa Rusconi, el concepto de laicidad es más exigente que el de multiculturalismo, ya que el principio laico "no se limita a neutralizar las pretensiones de las diversas culturas y religiones a ocupar de forma impropia o monopolista el terreno público, ni se limita a afirmar el principio de una tolerancia bien intencionada, sino que exige positivamente un vínculo recíproco sobre el que construir una comunidad política que es solidaria en cuanto se reconoce lealmente en los principios, las reglas y las instituciones que prescinden de raíces culturales particulares"31. A diferencia del principio laico, el indiferentismo es hijo del relativismo cultural, de las tesis, hoy tan de moda, según las cuales todas las culturas son iguales, desde el momento que cada una de ellas construye su propio sistema de valores. A su vez, el relativismo cultural enlaza con el relativismo cognoscitivo, para el que no existen certezas apoyadas en la objetividad científica, y al relativismo ético, según el cual no disponemos de un criterio "externo" con el que fijar jerarquías de valores. Sin embargo, no es difícil darse cuenta de las aporías de semejantes líneas de pensamiento. En un reciente ensayo Boudon ${ }^{32}$ muestra, deforma convincente, cómo es que las consecuencias derivadas de ciertos principios o valores confirman o invalidan aquellos principios 0 valores. Y, por tanto, que la inexistencia de principios o valores absolutos en ningún modo legitima la caída en el relativismo. Cuando ciertos principios morales se demuestran capaces, por los hechos, de generar resultados "positivos" o superiores a aquellos que derivan de otros principios, es prácticamente imposible no reconocer a estos una preeminencia objetiva. Es propiamente la prueba de los hechos la que decide si ciertos principios tienen más fundamento que otros y, por tanto, la que sanciona una suerte de jerarquía entre los principios. Ésta es una aplicación importante de la tesis del consecuencialismo "enriquecido", según el cual se valoran, bajo el perfil moral, no sólo las consecuencias en términos de preferencias satisfechas, sino también en términos de derechos humanos satisfechos. En vista de esto tiene sentido hablar de "progreso moral" como lo llama Boudon. La idea de intangibilidad de la vida humana, así como el principio de la igualdad

31 G. Rusconi (2000), Come se Dio non ci fosse; i laici, i cattolici e la democrazia, Turín, Einaudi.

32 R. Boudon (2000), Il senso dei valori, Bolonia, II Mulino. 
universal constituyen ejemplos elocuentes de progreso moral.

Es importante captar la diferencia entre relatividad de las culturas y relativismo cultural. Este último rechaza, en nombre de la simple pluralidad de las culturas, la existencia de los valores objetivos que estén a la base de las diferentes culturas. Con lo que el relativismo conduce, poco a poco, a la imposibilidad de diálogo cultural. En efecto, ¿por quésujetos pertenecientes a culturas diversas habrían de entrar en diálogo entre ellos, si ninguno cree en el progreso moral, es decir en la posibilidad de que a través de la confrontación leal y respetuosa de las posiciones en juego, se pueda llegar a mejorar los respectivos puntos de partida? La tesis de la relatividad cultural dice, por el contrario, que lo que es relativo es la específica traducción de valores y principios, que tienen consistencia propia, en las formas variables deuna cultura. Lorenzetti ${ }^{33}$ aclara bien esta cuestión cuando escribe que una cosa es el relativo respeto al absoluto, y otra es la afirmación según la cual nada es absoluto, como quiere el relativisimo. Por esta razón se puede decir que la fe cristiana es propiamente transcultural porque, no identificándose con ninguna cultura, convalidándola o legitimándola, puede encarnarse, es decir traducirse a todas las culturas como fuerza crítico-profética.

El cuarto principio afirma que el Estado laico, es decir neutral, al perseguir el objetivo de integrar las minorías étnico-culturales en el interior de una cultura nacional común, adopta como presupuesto para la integrabilidad que las culturas presentes en el país concuerden todas en un núcleo duro de valores, esto es lo hagan propio como núcleo de valores irrenunciables que, en cuanto tales, valen para todos los hombres, cualquiera que sea su pertenencia a una cultura específica. Se trata de aquellos valores que son fundamento de los derechos universales del hombre. A partir de este presupuesto, surge espontáneamente una pregunta: ya que nunca es lícito juzgar una cultura sirviéndose de otra como unidad de medida, y puesto que los derechos universales del hombre son una adquisición, aunque reciente, de la cultura occidental, ¿no existe quizá el riesgo de que el cuarto principio conduzca al imperialismo cultural? Como escribe oportunamente Palazza$\mathrm{ni}^{34}$, el hecho de que valores como la dignidad humana y teorías como la de

33 L. LorenzetTI, "Pluralismo culturale e unità del genere umano": Servizio Migranti 1 (2000). Véase también F. Vıola, "Ragione pubblica e diritti umani", en AA.VV. (2001), Etica pubblica e pluralismo, Padua, Messaggero.

34 L. Palazzanı, "Problemi bioetici e biogiuridici nella società multietnica" (mimeografiado), Università di Roma "La Sapienza”, Roma junio 2000. 
los derechos del hombre utilicen el lenguaje de la cultura occidental no es signo de prejuicio etnocéntrico; antes bien es sólo un indicativo de que Occidente ha llegado antes que otros contextos a tomar conciencia de tales valores, dotándolos de una fundamentación racional.Y, sin embargo, puesto que su justificación es racional, estos valores son extensibles, en la línea de los principios, a todos los hombres. En otros términos, la noción de derechos humanos no está ligada a Occidente, aunque sea el lugar de nacimiento de las cartas de los derechos. El contenido detales derechos no es específico deuna determinada cultura, aunque sea cierto que hoy hay un modelo cultural dominante de los derechos humanos, precisamente el occidental.

Pero aún hay más. En un reciente artículo, Sen 35 ha reafirmado que no es sostenible hoy la tesis de una radical separación entre Occidente y Oriente a propósito de valores fundamentales. Refiriéndose a la tradición filosófica india y, de forma especial, a los escritos de Kautilya (s. I. a.C.), Sen argumenta que considerar nociones como el liberalismo o valores como justicia, derechos humanos, dignidad de la persona y otros muchos, productos típicos de la cultura occidental, no impide de ninguna manera que no puedan ser adoptados en otros lugares, además de que estos derechos de hallan formulados de otra manera en otras civilizaciones. Así pues la aceptación de ese núcleo de valores por quien es portador de una cultura particular marca el principio por debajo del cual no es posible acoger legítimamente ninguna petición de reconocimiento institucional o público para una cultura. Por otra parte, por encima de aquel umbral la tarea a realizar es la de discernir lo que, en una determinada cultura, es tolerable, de lo quees respetabley, por último de lo que se puede compartir.

Claramente, la tolerancia abre un amplio campo de búsquedas, pues constituye el primer nivel de aceptabilidad para una determinada posición o actitud. La tolerancia, a partir de la prudencia, se configura como método para resolver los conflictos que derivan de la convivencia entre diferentes culturas. El respeto, sin embargo, es una red más fina que la tolerancia. De hecho, el respeto es la actitud mental quealimento en las confrontaciones entre posiciones diversas, a partir de lo cual, también eventualmente yo podría cambiar en la dirección de aquellas posiciones. Aún más estrecha es la red del compartir.

Como precisa Gutman ${ }^{36}$, para respetar una petición no necesitamos com-

35 A. Sen, “I valori tra Occidente e Oriente”, L'Avvenire, Milán 1-II-2001.

36 A. Gutman, "introduzione” a C. TAylor (1993), Multiculturalismo, Milán, Anabasi. 
partirla; debemos sólo conseguir que ésta respete un punto de vista moral que, aún no coincidiendo con el nuestro; no sólo que no contradiga los derechos humanos fundamentales, sino que signifique un progresivo modo de traducción de los mismos. Las demandas que pueden ser compartidas, sin embargo, son aquellas que realizan el proyecto de verdadera y propia hibridación cultural, o mejor, "integración con interacción", como recientemente ha afirmado el Consejo de Europa sobre este asunto. He aquí algunos ejemplos que nos pueden aclarar este punto. Mientras se puedetolerar -pero no, ciertamente, respetar, y menos, a fortiori, compartir- la expresión de ideas religiosas que discriminan a la mujer, no puede ser de ningún modo tolerada la praxis que deriva de esas ideas. Aún más, mientras podemos tolerar la posición de aquellos movimientos religiosos o de aquellas culturas que quisieran refundar el demos (el principio democrático) en el logos (la verdad religiosa), no es ciertamente respetable y mucho menos compartible la petición que quisiese reconducir las formas políticas a cualquier fundamentación sagrada. Aún más, mientras podemos compartir la demanda de reforma del currículo de las escuelas (historia o literatura, por ejemplo) para permitir cierto reconocimiento a las contribuciones culturales de las minorías etno-culturales, deberemos pararnos en el filtro del respeto en lo que atañe a la revisión de los módulos de trabajo, las reglas de vestido, la adaptación de los lugares de trabajo. Y así otros muchos aspectos.

Me interesa subrayar que la identificación de los tres niveles de consideración-tolerabilidad, respetabilidad, compartibilidad-tiene consecuencias de gran importancia en la práctica: ofrecen un criterio sobre cuya base proceder a la atribución de los recursos públicos a los diferentes grupos de minorías etno-culturales presentes en el país. Se podría, en la práctica, establecer que las demandas consideradas tolerables no reciben recursos, financieros u otros, del Estado o de otros entes públicos; las demandas respetables reciben reconocimiento en el ámbito administrativo, entrando así en el ordenamiento del Estado; las demandas definidas como compartibles son recibidas en el ordenamiento jurídico del país de acogida, con todo lo que ello comporta en términos de destino de recursos públicos.

Por último, ¿qué hacer con aquellas culturas que piden participar en el proyecto intercultural pero que no aceptan transformarse para acoger el estatuto de los derechos fundamentales? A ello da respuesta el quinto principio: el Estado, en nombre de los derechos del ciudadano -que, a diferencia de los derechos del hombre, no tienen una fundamentación iusnaturalista- destinarárecursos a los grupos portadores de aquellas culturas para 
ayudarles a evolucionar hacia posiciones capaces de acoger los derechos fundamentales del hombre. Éste es el significado del principio de "tolerancia condicionada": teayudo para que puedas abrir un espacio, dentro detu matriz cultural y según los modos propios de ésta, a la recepción de los derechos fundamentales. Es conocido que las culturas tienen tendencia a adaptarse al desarrollarse en las diferentes situaciones, pues no son algo estático. Y, por ello, la educación intercultural debe consentir a cada individuo afirmar la propia identidad y caminar más allá en cuanto ésta no se muestre capaz de comprender la universalidad de los derechos fundamentales.

¿Cuál es el sentido de un principio de este tipo? ¿Se trata de algo capaz de conducir a resultados prácticos o más bien se trata de pura utopía? Para decir algo más concreto, ¿hay esperanza de que también el musulmán de estrecha observancia pueda modificar en sentido evolutivo la propia posición hasta recibir aquel núcleo duro de valores a los que más arriba nos hemos referido? La relevancia de esta pregunta reside en que, en caso de respuesta negativa, el quinto principio quedaría vacío, mejor dicho anulado. Nos ayudará, en la búsqueda de una respuesta, la reciente reflexión de Viola ${ }^{37}$, para quien los derechos del hombre no son ya definidos haciendo caso omiso de las diferencias (de género, de religión, de raza, de cultura), sino como verdaderos y propios derechos de las diferencias. Es como decir que la historia de los derechos se mueve hacia una progresiva contextualización, ya no se mueve en el universalismo abstracto de un "se" humano desarraigado de la referencia a un contexto existencial cualquiera. Si las cosas están planteadas en estos términos, se debe entonces convenir que, en la línea de los principios, es realizable el proyecto de favorecer, para toda cultura, una evolución más o menos larga, al término de la cual se registre la convergencia sobre una base común de valores compartidos. Considérese el caso-ciertamentehoy el más delicado- de la cultura islámica. Como ha escrito Eisenstadt, "el fundamentalismo es un fenómeno absolutamente moderno", y los movimientos que lo practican "están caracterizados por una construcción política e ideológica extremadamente elaborada, que forma parte en todo y por todo, de la moderna agenda política", aunque sus orientaciones ideológicas básicas y sus símbolos "son antimodernos"38. En la misma línea se sitúa S. Khalil

37 F. VIOLA (2000), "Le origini ideali dei diritti dell'uomo", en Etica e metaetica dei diritti umani, Turín, Giappichelli.

38 S.N. EISENSTADT (1994), Fondamentalismo e modernità, Roma, Laterza; texto citado, en pp. 34. Una confirmación empírica de las tesis de este autor la hallamos en los recientes 
Samir cuando pide considerar los riesgos de la política del multiculturalismo, responsable, a su juicio, de dar aliento a la tendencia islámica reaccionaria que rechaza y combate la cultura occidental y la modernidad; por el contrario, dicha política del multiculturalismo desanima a "Ia tendencia liberal musulmana que representa a la mayoría de los musulmanes y que lucha desde hace dos siglos para proponer un Islam moderno. El Islam tiene, en sí mismo, la posibilidad de conciliar la religión con la modernidad. Occidente puede contribuir a hacer que se difunda el Islam tolerante. El camino es claro: no renunciar a ninguna adquisición de la civilización occidental: democracia, igualdad de género, libertad de pensamiento"39. En resumen, se proclama la integridad de la fecoránica no por fidelidad al depósito originario de la propia religión, sino para apoyar con fuerza un modelo de orden social bien definido. El fundamentalismo no es sólo peligroso porque quiera imponer una fe sobre otra, sino más aún por su apoyo funcional a un determinado proyecto político. Una confirmación autorizada de esta idea nos viene de Kadivar ${ }^{40}$, carismático dirigente religioso iraní, de rango apenas inferior al de ayatollah, cuando escribe que mientras el Islam es compatible con la democracia, esta última no lo es con el gobierno del jurisconsulto, el poder clerical, que es el principio cardinal de la República islámica. La misma tesis, ampliamente argumentada en sentido histórico, es defendida por Arkoun ${ }^{41}$, quien observa

acontecimientos de Afganistán, donde el mullah M. Omar, líder de los talibanes, ha ordenado la destrucción de todas las estatuas invocando la sharìa (la ley islámica). Sin embargo, M. Abdu (1849-1905), artífice del moderno movimiento de renacimiento islámico, en cuanto gran mufti de Egipto, había defendido que la prohibición de la representación figurativa humana debe ser históricamente interpretada, por haber estado justificada sólo en el contexto del paganismo preislámico. Tan es así que tanto el Islam sunnita turco-otomano como el Islam persa chiíta evolucionaron hasta la representación de Mahoma y su familia.

39 S. Khalel Samir, "entrevista" en La Repubblica 20-IV-2001, p.19. Puede ser interesante confrontar estas afirmaciones con las realizadas por el cardenal C.M. MARTINI al Corriere della Sera de 3-V-2001 (p.11): “La cultura islámica no es monolítica, como se piensa. Históricamente se ha ido diversificando mucho y así sigue siéndolo ahora ... Ya en los siglos pasados en el Islam se afirmaron corrientes más atentas a la racionalidad... Se trata de no bloquear estos desarrollos con un juicio global negativo, sino de valorar el diálogo".

40 M. Kadivar, "Islam come democrazia", en II Sole 24 Ore, 8-VII-2001.

41 M. Arkoun (1996), Islam, morale et politique, París, Desclée de Brouwer. Asimismo Hasan Turabi, uno de los más notorios exponentes islamistas que postulan un modelo islámico que no se distinga por la primacía de la religión sobre la política, parte de la premisa según la que la misma sharia, en cuanto pertenece al ámbito divino, no debe influir en manera alguna en la construcción de las instituciones politicas. Véase sobre este argumento el interesante ensayo de A. SAlvatoRe (1997), Islam and the political discourse of modernity, Reading, Ithaca Press. 
que los Estados árabes utilizan desde siempre al Islam en sus estrategias de control o de supervivencia, lo que viene a ser lo mismo que decir que lo político domina a lo religioso y no al revés, como se tiende a creer.

He aquí porque soy de la opinión de que el principio de la tolerancia condicionada representa el punto de equilibrio más avanzado entre la exigencia, por un lado, de tener en cuenta las dificultades de rápida adaptación al nuevo contexto cultural en que viene a encontrarse el inmigrado y, por otro lado, de no conceder descuentos a quien pide o desea integrarse en la sociedad de acogida para convertirse en ciudadano de la misma, sobre cuestiones centrales como las referidas a los derechos universales de la persona. Como afirma Rusconi: “Ser ciudadanos no significa sólo disfrutar de bienes y derechos subjetivos, sino comprometerse a contribuir a su producción"42. Y es claro que para contribuir a la producción de un derecho subjetivo es necesario cuando menos reconocer la pertinencia del mismo.

\section{Los puntos fuertes del modelo de integración intercultural.}

Tomados en su conjunto, los cinco principios arriba mencionados nos permiten profundizar en los puntos fuertes del modelo que llamo de integración intercultural. En un importante documento de 1986 del Consejo de Europa ${ }^{43}$ se lee que la opción intercultural implica el "reconocimiento de los valores, los estilos de vida, las representaciones simbólicas a las que se refieren los seres humanos... en sus relaciones con el otro". Pero, ¿qué significa reconocer? En el texto se proponen ejemplos y se dan consejos prácticos para realizar un programa intercultural; no se resuelve el interrogante de fondo. La propuesta que avanzo, sin embargo, llega a definir con rigor qué debe entenderse por "reconocimiento" y sobre todo permite prefigurar un espacio público que no sea el de una ciudadanía "indiferentista", privada de una base ético sólida, sino el de una ciudadanía "laica" capaz de valorar las identidades culturales y, en particular, las pertenencias religiosas, a condición que éstas satisfagan las condiciones implicadas en los principios cuarto y quinto, es decir, que no atenten contra los derechos humanos.

42 G.E. Rusconı, “Multiculturalismo e cittadinanza democratica” (1996): Teoria Politica, 3; texto citado, en p. 24.

43 El CE, creado en 1949, es el organismo que actualmente agrupa a 40 Estados europeos. Cfr. I. DASSORI (ed.) (2000), Europa interetnica. Documenti del Consiglio d'Europa, Milán. Texto citado, en p. 33. 
Además, la presente aproximación evidencia una notable finalidad integracionista, desde el momento que los grupos de inmigrados presentes en el país de acogida no son animados a sentirse como "naciones separadas" que se autogobiernan, como sucede, por ejemplo, con los Amish y con la comunidad Lubavic de Brooklyn, en los Estados Unidos de América del Norte. En contra de lo que exigiría una política de inspiración comunitarista, la política intercultural, como aquí ha sido explicitada, implica una revisión de los términos de la integración, pero no un rechazo de la integración en la sociedad de acogida en sí misma. Ello se debe a que una política intercultural no puede tratar a las diferentes culturas como "islas cognitivas" incomunicables entre sí. Al mismo tiempo, la política intercultural está en posición de desactivar el riesgo proclamado por los sostenedores de la posición neoliberal, el riesgo de que el reconocimiento de la identidad etno-cultural de los inmigrados pueda conducir al separatismo y, por consiguiente, a diluir la identidad nacional. No es así porque, como se ha subrayado más arriba, el reconocimiento del que se habla se produce en el interior delas instituciones comunes ya existentes. Lo que cambia no son los principios reguladores de las mismas instituciones, que permanecen estables, sino los modos tradicionales de aplicación de estos principios, los modos dictados en función de una particular tradición cultural. Sólo quien cultivase una concepción estática, y por ello superada, de identidad nacional, seguiría defendiendo la pureza de las propias tradiciones del contagio de otras tradiciones.

Para realizar un ensayo sobre la solidez del modelo propuesto, intentemos someterlo a la prueba de un caso concreto: la relación entre las instituciones liberales de nuestra sociedad y el islamismo en su versión ortodoxa. Los términos de la llamada cuestión islámica son hoy suficientemente claros por lo que es innecesario volverlos a proponer ${ }^{44}$. Me limito sólo a subrayar algunos puntos esenciales, útiles a la finalidad del ejercicio propuesto. Un elemento característico de la visión del mundo que tiene el Islam militante es la concepción totalizante y monolítica que el fiel tiene de la religión. Como nos recuerda Lewis ${ }^{45}$, Mahoma, a diferencia de todos los profetas de las otras religiones, fue también fundador y guía de una entidad política y, en cuanto

44 Véase el bien documentado ensayo di G. CANTon (2000), Aspetti in ombra della legge sociale dell'Islam, Caltanisetta, Centro Studi Cooperazione, y la amplísima literatura allí citada. Asimismo el documento de la Conferenza Episcopale Emilia-Romagna (2000), Islam e Cristianesimo, Bolonia, EDB.

45 B. LewIS, "La questione religiosa": II Mulino no 6 (2000). 
tal, promulgó leyes, ejercitó funciones judiciales, fue caudillo militar, declaró la guerra y firmó la paz, etc. No debe, pues, sorprender que en el Corán ${ }^{46}$ se lea que el fiel musulmán tiene el deber primario de "imponer el bien e impedir el mal". La invitación, por tanto, no es para hacer el bien y para evitar el mal, como lógicamente muchas creencias religiosas recomiendan, sino para imponer y para impedir, lo que equivale a ejercer la autoridad a tal fin. "Es imposible para un musulmán realizar su intención de observar un modelo de vida islámico bajo la autoridad de un sistema de gobierno no islámico"47.

Es, sobre todo, por esta razón que, en el Islam ortodoxo, Estado y fe religiosa no pueden permanecer separados; el primero, de hecho, es instrumento y camino para realizar el proyecto de Dios en la historia. Como lúcidamente dice Ahmad en la introducción al célebre libro de Mandudi, verdadero punto de referencia para el pensamiento islámico: "Las reformas que el Islam quiere aportar no pueden ser efectuadas sólo con predicaciones. Para realizarlas es indispensable el poder político"48. En el célebre libro de Huntington se habla, a este propósito, de las "fronteras ensangrentadas del Islam"49, para indicar que allí donde el Islam político está en contacto con otras culturas hay derramamiento de sangre. Ciertamente, la sociedad islámica tradicional no admite el pluralismo: el mundo está dividido en dos esferas separadas, la "esfera del Islam" ( Dar al-Islam), en la que los musulmanes viven en mayoría como una comunidad (umma, comunidad islámica) y ejercitan el poder político, y la "esfera de la guerra" (Dar al-Harb) que incluye a todos los otros. Claramente, el objetivo, o mejor la misión, a conseguir es la de dilatar lo más posible la primera esfera a costa de la segunda ${ }^{50}$. Una posición de este tipo refuerza la tesis por la que para el Islam, a diferencia de cuanto ocurre al cristianismo, el test decisivo no es la adhesión a una fe sólida, fundada racionalmente, sino la fidelidad a una comunidad islámica en la que lo razonable es la fe. Y ya que el conformismo religioso, observa Lewis, es el signo exterior de distinción entre fidelidad y la apostasía, se deduce de ello que la herejía, la ruptura de esta fidelidad y la apostasía son una grave

46 Suras 3:104; 7:157; 22:41.

47 A. Mandudi (1980), Jihad in Islam, Beirut, The Holy Coran Publ. House, p.19. Véase también G. BIFFI (2000), Dell'immigrazione, Bolonia, EDB.

48 A. Mandudi (1980), The Islam law and Constitution, Lahore, Islamic Publications, p.5.

49 S. Huntington (1996), The clash of civilizations, Nueva York, Simon \& Schuster, p. 254.

50 Cfr. W. Montgomery Watt (2001), Breve storia dell'Islam, Bolonia, II Mulino 
traición. Es así como llegamos a darnos cuenta del hecho que en el proyecto de código penal unificado de los países árabes se establece que "el apóstata es castigado con la pena de muerte si se prueba que ha renegado [del Islam] de forma voluntaria y ha confirmado [su renuncia al Islam] tras haber sido invitado a arrepentirse en un plazo de treinta días"51. Si no fuese por la centralidad de la tesis citada arriba, no sería fácil llegar a comprender la ratio de una verdad de semejante severidad e intransigencia.

En definitiva, el hecho de que el Islam ortodoxo e integrista se defina a sí mismo como "religión y cultura y política", esto es, como proyecto culturalpolítico de transformación de la sociedad, y aún el hecho de que no exista propiamente, ni siquiera en el ámbito conceptual, una distinción análoga a la que hay entre Cristianismo, en cuanto religión, y cristiandad, como la civilización desarrollada bajo la influencia cristiana, lleva, fácilmente, a afirmar que, "si el Estado islámico es necesario para realizar el mensaje de Dios, entonces el ser ciudadano no se basa en el ius sanguinis o en el ius loci, sino en el ius religionis"52.

Pues bien, con el modelo propuesto en este artículo, no debería ser difícil decir, caso por caso, qué demandas de reconocimiento público entre las avanzadas por los inmigrados que vienen del mundo islámico son aceptables, como es el caso para aquellas que superen el test que representa el respeto a los derechos universales del hombre, y qué demandas, sin embargo, no son de recibo, como en el caso de las que, presentadas bajo la etiqueta de identidad cultural, permitirían a un grupo "oprimir" a sus miembros. No sólo, pero especialmente entre las demandas juzgadas como "recibibles", el modelo de integración intercultural permite fijar una especie de orden de prioridad basado en el diverso grado de "receptibilidad" de las mismas: tolerables, respetables y compartidas, bien entendido que, como ya se ha dicho, a cada grado corresponden niveles diversos de recursos público específicamente destinados a la implementación de las relativas políticas públicas. Tengo motivo para mantener que una aproximación de este tipo podría ser utilizada convenientemente para resolver las cuestiones nucleares, en discusión hoy en Italia, acerca de la acogida, mayor o menor, en los protocolos de una eventual comprensión de los parámetros de la identidad

51 Cfr. art. 162.

52 P.J. Vatikıotis (1993), Islam: stati senza nazioni, Milán, II Saggiatore, p.47. Cfr. el ensayo de G. BIFFI, cit. en n. 45. 
musulmana. Piénsese en las demandas sobre la materia: libertad religiosa (reconocimiento de las fiestas religiosas; permiso para ausentarse del trabajo para la oración), matrimonio (poligamia, consenso matrimonial dela mujer musulmana, impedimento matrimonial por disparidad de religión, derecho de repudio a la mujer por parte del varón musulmán), ordenamiento escolar (contenidos de las materias de enseñanza, separación entre hombres y mujeres en las aulas; el velo para las muchachas; vacación académica los viernes), alimentación (sacrificio de reses, alimentos autorizados), cementerios (la "sepultura perpetua", la inhumación directamente con el sudario), etc. ${ }^{53}$

Quiero añadir dos consideraciones importantes sobre el modelo. La primera es que hay que dejar claro y explícito a todos, de forma anticipada, tanto a las autoridades político-administrativas y de la policía como a aquellos que intentan establecerse en el país de inmigración, qué reglas y criterios se tomarán en consideración, de modo que se eliminen peligrosos espacios de discrecionalidad. Para ilustrar la dificultad de este criterio puede consultarse el documento del Consejo de Europa que lleva por título Las relaciones intercomunitarias e interétnicas en Europa ${ }^{54}$, en el que se lee: “El Estado... debe ser particularmente vigilante y cuidadoso con las prácticas culturales que limiten el derecho del individuo a realizar sus opciones fundamentales", y más adelante añade: "El derecho islámico de la familia comporta algunos elementos totalmente incompatibles con el principio europeo de derechos inalienables del individuo y con la igualdad de sexos. Parece dificilísimo poder llegar a un compromiso en este punto"55. Con afirmaciones genéricas

53 Para una referencia de las demandas que, en la práctica, las comunidades islámicas han suscitado y presentado insistentemente a las autoridades francesas y alemanas, véase K.P. EDWING, "Legislating religious freedman: muslim challenges to the relationship between Church and State in Germany and France", Dedalus: $\mathrm{n} 03$ (2000). Para lo referido a Italia, hay que notar que el liderazgo del Islam italiano organizado continúa siendo expresión de la corriente neotradicionalista, por lo que se complica no poco la definición de los términos de un eventual acuerdo. En efecto, tres son los proyectos de acuerdo que hasta ahora se han presentado: dos son expresión de grupos que reclaman la máxima separación posible de un espacio "impuro", como nuestra sociedad occidental; el tercer proyecto pertenece a un grupo (Co.RE.IS) que busca con dificultades insertarse en el movimiento de pluralismo religioso europeo. El hecho de que los tres grupos representen sólo una cuarta parte de los musulmanes de Italia complica aún más las cosas.

54 Documento de 1991, cfr. I. DASSORI (ed.) (2000), Europa interetnica. Documenti del Consiglio d’Europa, Milán.

55 lbid. , pp. 175 y 179 respectivamente. 
de este tipo ciertamente no se puede esperar que las recomendaciones de una institución importante como es el Consejo de Europa puedan ser tomadas en consideración, y menos aún ser traducidas a la práctica ${ }^{56}$.

La segunda precisión, a la que más arriba hacía alusión, es hacer concretamente posible el diálogo intercultural con aquellos sectores del mundo islámico, y sin duda existen algunos, que han hecho de la apertura en sus relaciones con el mundo occidental su razón de existir. Ciertamente, el grave riesgo que se esconde en las trampas de la vulgata "islámicamente correcta" es la relativización del concepto de derechos de la persona para convertir en más cómodo y más practicable el diálogo. Lo que no es de ninguna manera posible, pues confunde el diálogo con la charla. Haciendo explícito, desde el principio del diálogo, el sistema de principios de los que se parte, se facilita, además de la mutua comprensión, como es obvio, la constatación, por parte del que ha llegado, de qué derechos humanos e instituciones fundadas en el principio de libertad tienen valor vinculante también para aquellas culturas que declaran no querer acogerlos. Son instructivos, a este propósito, los sucesos que han acompañado la Declaración de derechos y deberes del hombre del Islam de 1990, adoptada por la Conferencia Islámica que reunió a sus 51 Estados miembro. En ella fue confirmada, entre otras cosas, la superioridad de la ley coránica sobre cualquiera otra ley, fuese natural o positiva. En 1994 la Liga Árabe, organismo de coordinación esencialmente política y no religiosa, aprobó el texto de una Carta árabe de los derechos del hombre, en el que no hay ninguna referencia a la ley coránica, apelándose sólo a los principios eternos sancionados por el derecho musulmán, equiparados a los de las otras religiones monoteístas. Al día de hoy, esta Carta no ha entrado aún en vigor, a causa de la ausencia del número necesario de ratificaciones ${ }^{57}$.

56 Cfr. I. ORLANDo, "L'educazione interculturale e la normativa scolastica in italia": Studi Emigrazione no 140, (diciembre 2000).

57 Sobre el tema. Véase la importante discusión de F. VıoLA, "Diritti umani, universalismo, globalizzazione e multiculturalismo", en F. VIoLA (2000), Etica e metaetica dei diritti umani, Turín, Giappichelli. Los historiadores nos recuerdan quela Declaración Universal de Derechos del Hombre de 1948 nació en circunstancias históricas ciertamente peculiares, entre el final de la segunda guerra mundial y el comienzo de la guerra fría. Y bien, también en un contexto de este tipo los Estados islámicos se propusieron votar contra la Declaración, apoyándose en la imposibilidad de acoger en particular el arto 18, que garantiza el derecho de cada persona a cambiar la propia religión, lo que para el Islam equivaldría a legitimar la apostasía (ridda). Sólo por la extenuante mediación de los delegados del Paquistán y del Líbano se llegó, finalmente, a la inclusión por parte de los ocho Estados islámicos; cfr. la notable reconstrucción de M.A. Glendon (2000), Rights from wrougs, Nueva York, Random House. 
Para concluir, no hay quien no vea cómo la búsqueda de un equilibrio satisfactorio entre un código común de convivencia y la instancia de la multiplicidad cultural plantea problemas delicados y de gran alcance. No debemos esconder que las demandas identitarias infunden siempre miedo en aquellos a los que son dirigidas. A veces, estos miedos toman el camino de la negación o de la ignorancia de la identidad del otro; otras veces, conducen a la adopción de prácticas meramente asistenciales que humillan a aquellos que son sus destinatarios porque anulan la estima que estos tienen de sí mismos. Y, sin embargo, como nos recuerdaJ uan Pablo II, en el ya citado mensaje: "el diálogo entre las culturas... emerge como una exigencia intrínseca de la misma naturaleza del hombre y de la cultura"58.

La tarea, que en este escrito he intentado realizar, ha sido poner sobre la mesa de debate la propuesta de un camino capaz de conjurar la Escila del imperialismo cultural, que lleva a la asimilación de las culturas diversas respecto de la dominante, y la Caribdis del relativismo cultural, del que resulta la balcanización de la sociedad. El modelo deintegración intercultural que he esbozado está fundado en la idea del reconocimiento del grado de verdad presente en toda visión del mundo, una idea que permite que convivan el principio de igualdad intercultural, formulado a partir de los derechos humanos universales, con el principio de diferencia cultural, aplicado a traducir la praxis jurídica de los derechos humanos. La aproximación a la verdad desde el reconocimiento, adoptada en este escrito, no tiene otra condición si no es la racionabilidad cívica de la que habla Galston: todos aquellos que piden participar en el proyecto intercultural deben poder aportar razones para sus demandas políticas; ninguno está autorizado a limitarse a afirmar lo que prefiere 0 , peor, a proferir amenazas. No sólo éstas, pero también estas razones tienen que tener carácter público, ya que esto viene exigido por la "civilidad", es decir, han de ser justificables mediante palabras que personas de diferentes creencias o culturas puedan comprender y acoger como razonables, y por tanto tolerables, incluso si no son, para ellos, plenamente respetables o compartibles. Sólo así, pienso, las diferencias identitarias pueden ser sustraídas al conflicto y a la regresión.

58 Mensaje para la Jornada Mundial de la Paz (1 de enero de 2001), "Diálogo entre las culturas para una civilización del amor y de la paz", no 10. 